The Canadian Society for Bioengineering
The Canadian society for engineering in agricultural, food, environmental, and biological systems.

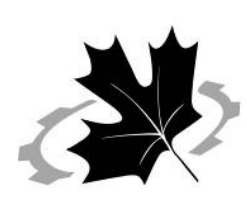

La Société Canadienne de Génie Agroalimentaire et de Bioingénierie

La société canadienne de génie agroalimentaire, de la bioingénierie et de l'environnement

Paper No. 06-122

\title{
Network Analysis of Grain Bulk Pore Structure Using High Resolution X-ray Computed Tomography Images
}

\section{S. Neethirajan}

Graduate Student, The Canadian Wheat Board Centre for Grain Storage Research, Biosystems Engineering, University of Manitoba, Winnipeg, MB, R3T 5V6, Canada

\section{S. Jayas}

Distinguished Professor, Canada Research Chair in Stored-Grain Ecosystems, Associate Vice-President (Research), University of Manitoba, Winnipeg, MB, R3T 2N2, Canada

\author{
Written for presentation at the \\ 2006 CSBE - SCGAB Annual General Meeting \\ Sponsored by CSBE \\ Edmonton, Alberta \\ July 16-19, 2006
}

\begin{abstract}
The knowledge of distribution of pore space inside grain bulks is essential for determining the effect of porosity on the airflow resistance of grains. In this study, the geometry of pore structure and the 3D-distribution of void spaces inside the grain bulks were studied using high resolution $X$-ray computed tomography (CT) images. The quantitative analysis of the architecture, geometry and spatial continuity of the pore network inside grain bulks was done using image processing algorithms. Image analysis methods were applied to the binary 3D X-ray CT images on the spatial distribution of voids to generate the connected, individualized pore objects of different size and shapes. Morphometric parameters such as 3D air path volume distribution, air path thickness, Euler number, fragmentation index, structure model index were calculated three dimensionally based on hexahedral marching cubes volume model and marching cubes 3D surface construction algorithm. The results showed that the connectivity of airspace and the non uniform distribution of void space inside grain bulks were responsible for the difference in resistance to airflow of grain bulks between horizontal and vertical directions.
\end{abstract}

Keywords. pore network, airflow resistance, grain bulks, 3D image analysis, X-ray CT, connectivity. 


\section{Introduction}

Recent advances in imaging methods and the computational capability have resulted in the ability to measure parameters which were otherwise impossible. Void phase, the distribution of individualized pore network and its geometry inside a granular media such as grain bulks are significant parameters for biological engineers.

Jayas et al., (1987) have done experiments for determining the effect of configuration of voids and grain surface roughness characteristics on the resistance to airflow of grains. They concluded that the voids and the distribution of pore network concerning the airflow resistance inside grain bulks have to be studied. Experimental techniques are needed for more reliable observation concerning the interior of the bulk of granular solid in designing the grain silos (Nielson, 1998). The need for measurement and the study of architecture and the geometry of the individualized pore network inside grain bulks will assist in modeling of cooling or fumigation patterns inside grain bulks.

The inherent heterogeneity of porous media as well as the complexity involved in quantifying the porosity and the pore morphology inside the grain bulk is a significant challenge. X-ray computed tomography (CT) can reliably describe the pore structure and connectivity of real samples (Turner et al. 2003). Significant research has been done to analyze the pore network using tomography images in soil cores and water flow in porous media (Lindquist, 2002, Kainourgiakis et al., 2005 and Toye et al., 2005). In this study we have focused on 3D measurement of the morphometric features of the air flow pathways inside grain bulks using $X$ ray CT images. This morphometric information will explain the fundamental relationship between architecture, geometry of pore topology and the spatial continuity of the flow path network inside grain bulks.

The objectives of this study were:

1) to generate $3 D$ models of intergranular airspace inside the grain bulks using $X$-ray CT images and

2) to measure morphometric features for quantifying pore geometry and correlations that occur at the pore scale inside the grain bulks

\section{Materials and Methods}

\section{Samples}

Barley, flax seed and mustard seeds were selected for CT scanning based on their shape to give potentially different airflow paths. Of these samples barley and flax seed are oblong in shape while mustard is almost spherical. The sample containers were made of acrylic material, which is radiometrically translucent to the X-rays. The resolution of the X-ray CT image depends on the size of the sample. For smaller seeds like flax seed and mustard, the resolution of the image must be higher to get a clear image. So, the effectiveness of the high resolution 3D X-ray tomographic measurement of void space inside grain bulks was evaluated by selecting an appropriate sample size. Hence, two sizes of sample containers were used for scanning. Barley was filled in a separate $15 \mathrm{~cm}$ side cubic acrylic container while flax seed and mustard were filled in two, $7.5 \mathrm{~cm}$ side cubic containers. The containers were sealed tightly by placing cotton on the top of the compact grain bulk with a lid to avoid the change in orientation of kernels while scanning. 


\section{Imaging}

The X-ray CT images of all the grain bulk samples were scanned using Bio-imaging Research X-ray CT scanner (University of Texas, Austin) at $420 \mathrm{kV}$ and $1.8 \mathrm{~mA}$. Rather than rotating the $X$-ray source and detectors during data collection, as in medical CT technology, the sample container was rotated. The samples were scanned only at the middle of the container for a 50 $\mathrm{mm}$ (barley bulk) and $43 \mathrm{~mm}$ (mustard and flax seed bulk) thickness to avoid the wall effect but in both the horizontal and vertical directions (Figure 1). The barley bulk was scanned at $200 \mu \mathrm{m}$ resolution with $0.25 \mathrm{~mm}$ slice thickness, while flax seed and mustard seed bulks were scanned at $120 \mu \mathrm{m}$ resolution with $0.125 \mathrm{~mm}$ slice thickness. Totally there were $1800 \mathrm{CT}$ images, 200 images in each direction of scanning for barley bulk and 350 images in each direction of scanning for flax seed and mustard bulks. Each voxel size is $0.04 \mathrm{~mm}$.

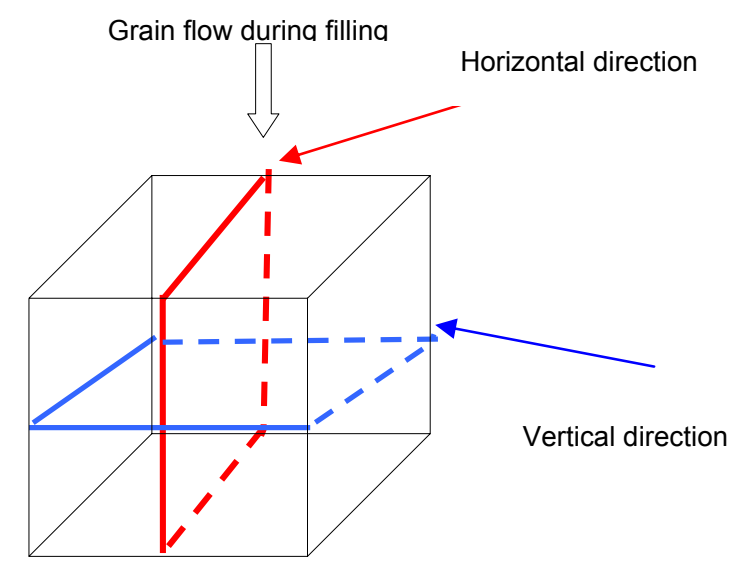

Figure 1. Schematic of the relationship between CT image and airspace.

\section{$3 D$ reconstruction}

Marching cube algorithms (Lorensen and Cline, 1987) developed by CT Analyser (version 1.4, Skyscan, Belgium) were used for preprocessing of data, reconstruction of 3D model and morphometric feature extraction from voids inside the grain bulk from the X-ray CT images.

Adaptive threshold was used to differentiate and classify the void space from the grain space. The image was segmented to isolate and trace the boundaries of the volume of interest within the image set. Rather than working with all the pixel values the rendering algorithms defined the boundaries of objects in vectors - a closed polygon with a given magnitude for all image slices. The 3D reconstruction model began by reading slices of data into memory such that each slice was stacked one on top of another to form a large volume. To create the 3D polygon based surface model, the surface rendering algorithm searched the best corresponding point in the neighbor slices to connect for forming surface triangles. When all boundary points were connected, a watertight surface model was created. For volume rendering, each pixel in a slice became a voxel element in the volume. Cubic voxels were produced based on interpolation. This interpolation allowed new slices to have an inter-slice spacing equal to the pixel size (Drebin et al., 1990). Both volume model and surface rendering models were generated using the algorithms. Both models can be sliced to show the image voxels on the model or at certain position within the intergranular airspace 3D model. Image processing steps for creation of 3D model from the X-ray data is shown in the Figure 2. The above image processing steps were implemented for the creation of 3D reconstructed models for all the grain types. 


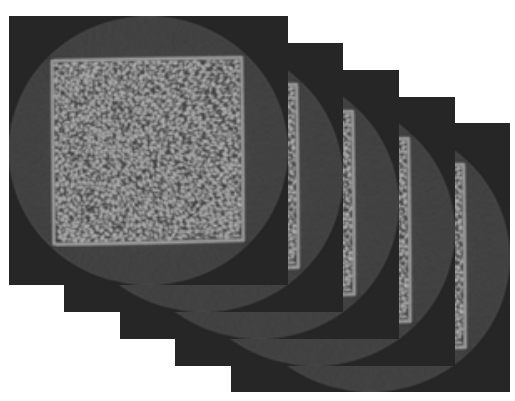

Serial stack of 3D X-ray CT images
Cropping + Adaptive

thresholding

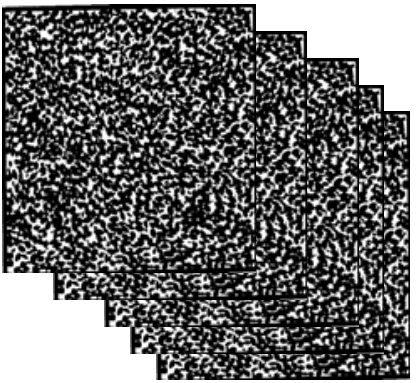

Binary pore space

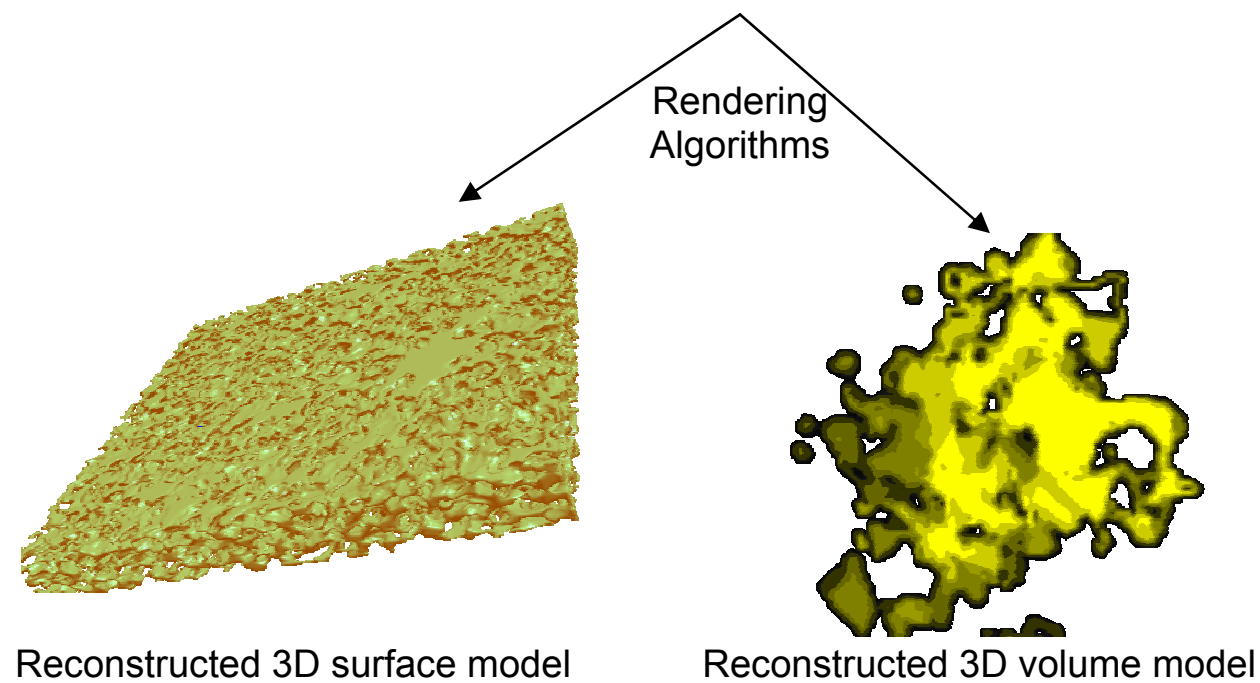

Figure 2. Schematic diagram for visualization of pore structure from 3D X-ray data.

\section{Morphometric feature extraction}

Both the qualitative information and quantification characteristics of the air path network model inside grain bulks were obtained with the help of the mathematical morphological functions of the algorithm from the developed models. The qualitative information includes the structure model index, general shape, Euler number while the quantitative characteristics are total number of air paths, individual airspace surface area, overall airspace volume, thickness of airspaces and fragmentation index.

Connectivity of airspace inside grain bulks is an important factor when designing fumigation and cooling pattern. Two points of the pore space are connected if a continuous path inside the void space goes from one point to the other one. Connectivity is quantified by Euler number and fragmentation index.

All the grain sample images were analyzed using the above image processing techniques and morphometric structural parameters for each grain bulk were extracted for both the horizontal and vertical directions. An independent group t-test was done to check the difference between the means of the morphometric parameters in both horizontal and vertical directions for all grains (SAS version 8.2, Statistical Analysis Systems, Cary, NC). 


\section{Results and Discussion}

The bulk densities of barley, flax seed and mustard samples were 590, 625 and $670\left(\mathrm{~kg} / \mathrm{m}^{3}\right)$ from the image which is equivalent to the reported bulk densities of 610 (Kumar and Muir, 1986) 642 (Irvine et al., 1992) and 684 (Velasco et al., 1998) $\mathrm{kg} / \mathrm{m}^{3}$ respectively. Based on these data it was assumed that the grain samples used for this study reasonably represented the bulk grain.

The binary image of the pore space (Figure 2) is not connected, but the 3D analysis of developed models shows that most of the pore spaces are well connected. Pore body and pore throat can also be observed by cutting section image of the 3D model (Figure 3). Because of the large amount of data and computational complexity involved in measurement of parameters, computer memory is a concern. For faster processing of algorithms and volumetric image analysis, high performance computing is essential.

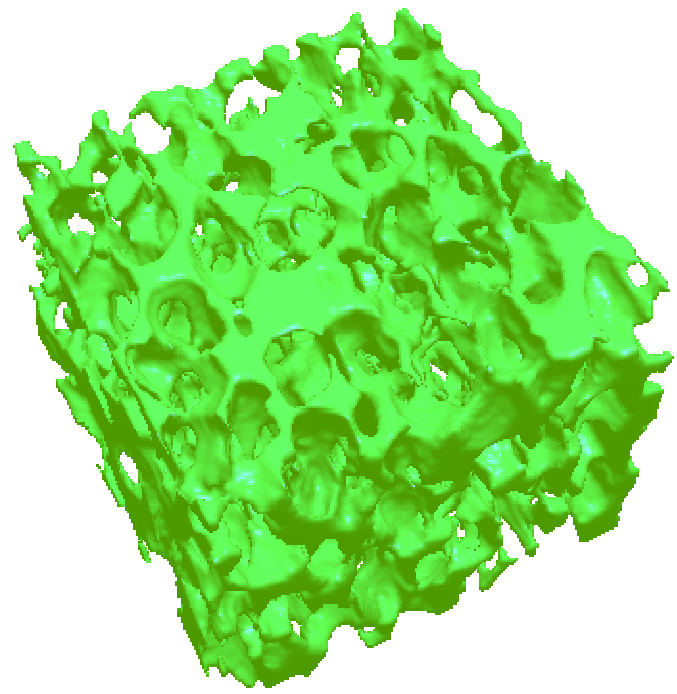

(a)

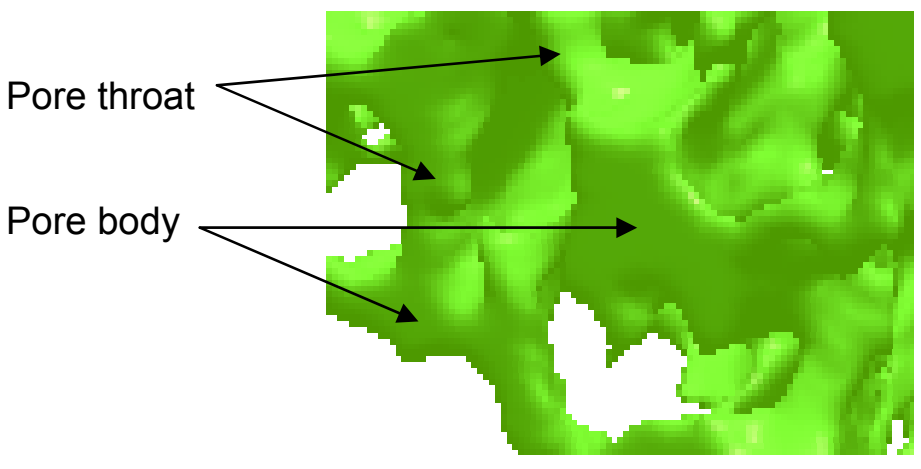

(b)

Figure 3. 3D reconstructed surface model showing well connected pore structure (a) full model,

(b) cut section image of 3D model.

Relationship between pore structure properties and airflow resistance in grain bulks is analysed. The resistance offered to airflow passing through the grain bulks in vertical direction is more than in the horizontal direction. For Barley, flax seed and mustard the airflow resistance ratios (horizontal /vertical) are 0.47 (Kumar and Muir, 1986), 0.38 (Jayas et al., 1991) and 0.72 (Velasco et al., 1998) respectively. The effect of pore space features in determining the airflow resistance difference in grain bulks are discussed in this study.

\section{Morphometric features analysis}

\section{D air path volume distribution}

The 3D air path volume distribution inside barley, flax seed and mustard grain bulks is shown in the Figure 4. The number of air path volumes is higher in horizontal direction than in the vertical direction for barley and flax seed bulks. This explains the reason for larger resistance to airflow in the vertical direction than the horizontal direction of grain bulk. Designing drying and aeration systems which force air horizontally through grain bulks will be more energy efficient. In mustard 
bulk, only few number of smaller air path volumes ( 0 to 4 voxels) are higher in horizontal direction than in the vertical direction. The percentage difference in air path volumes from horizontal to vertical direction ranges from 34 to $58 \%$ for barley bulk and 22 to $64 \%$ for flax seed bulk. There is no significant difference in air path volumes in both the horizontal and vertical direction of mustard bulk. At an airflow rate of $0.2 \mathrm{~m}^{3} /\left(\mathrm{s} . \mathrm{m}^{2}\right)$, barley offers a resistance of 700 $\mathrm{Pa} / \mathrm{m}$ (ASAE 2003), while flax seed offers a resistance of $2000 \mathrm{~Pa} / \mathrm{m}$ (Jayas et al., 1991) in the vertical direction of the grain bulk.

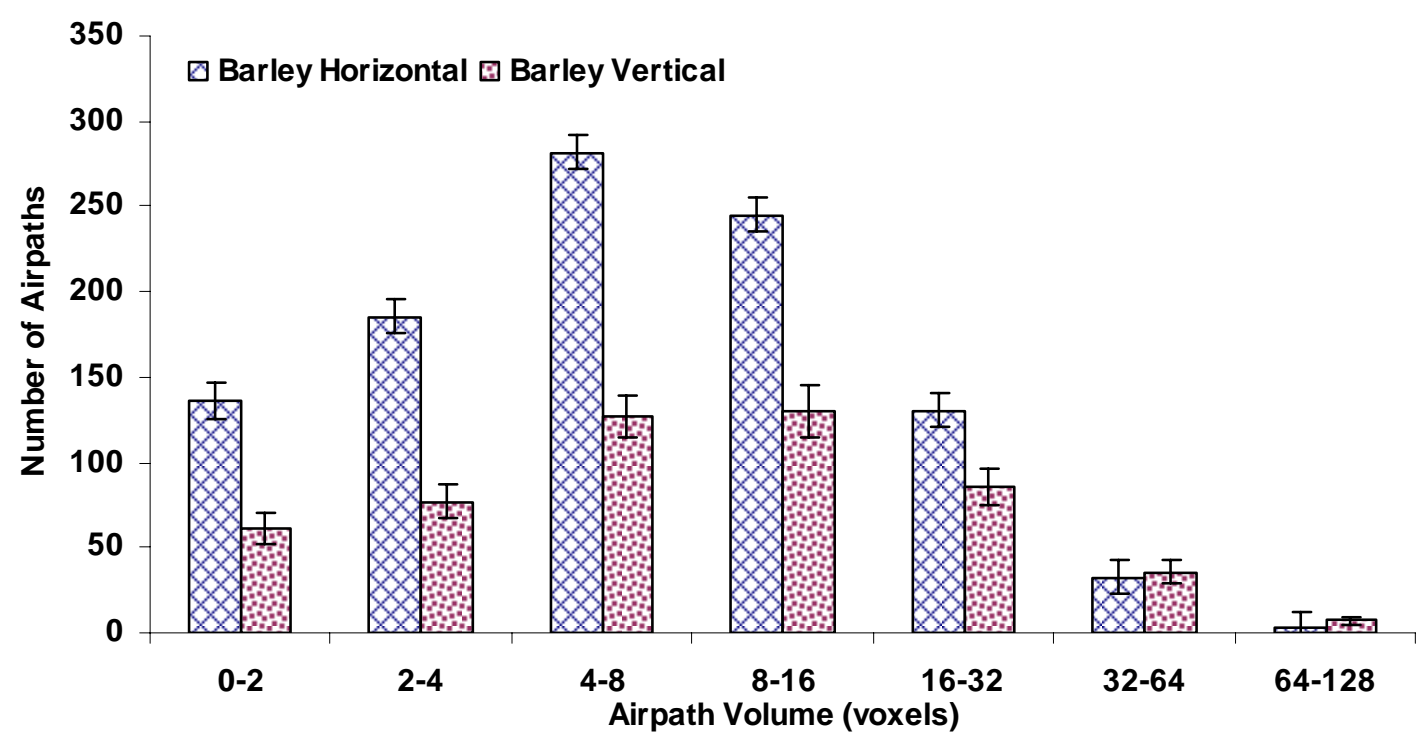

(a)

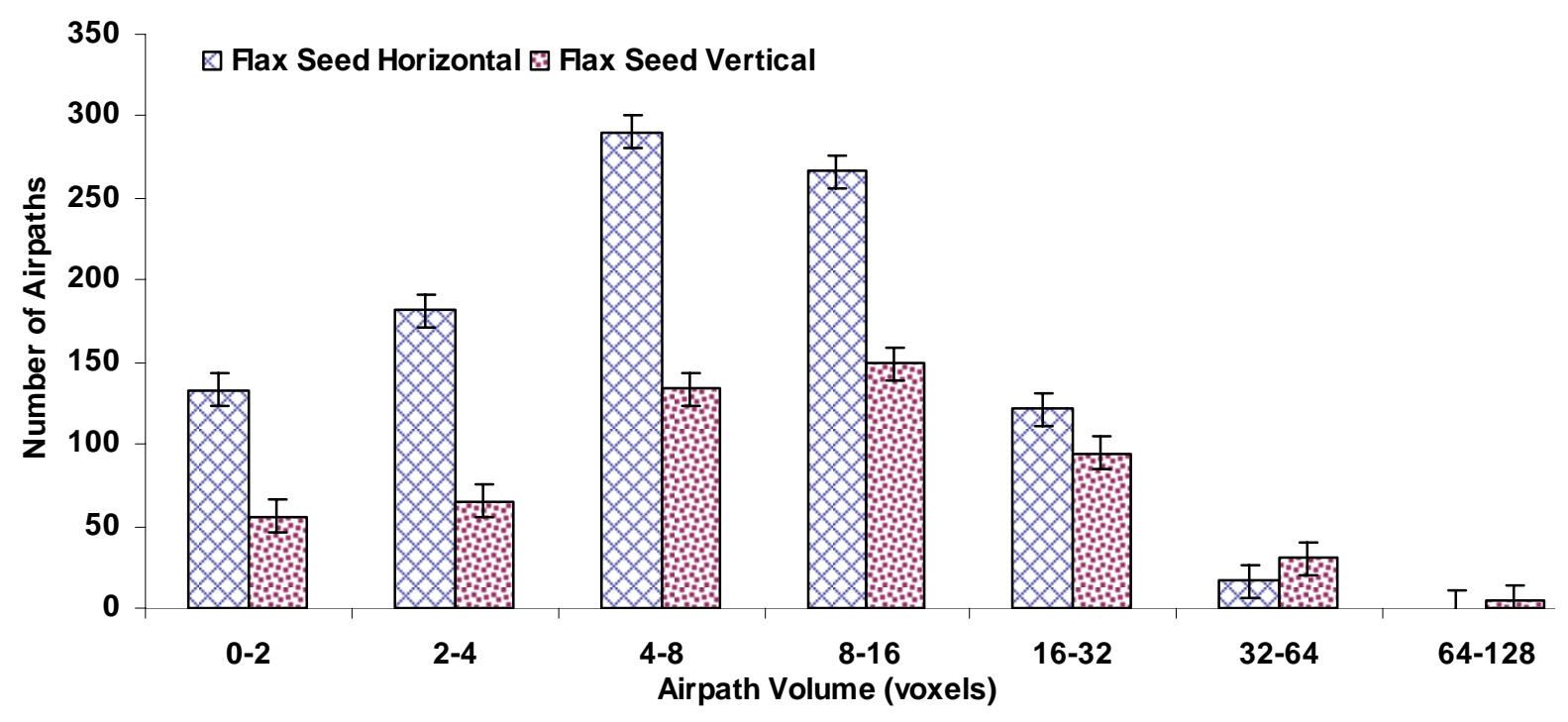

(b) 


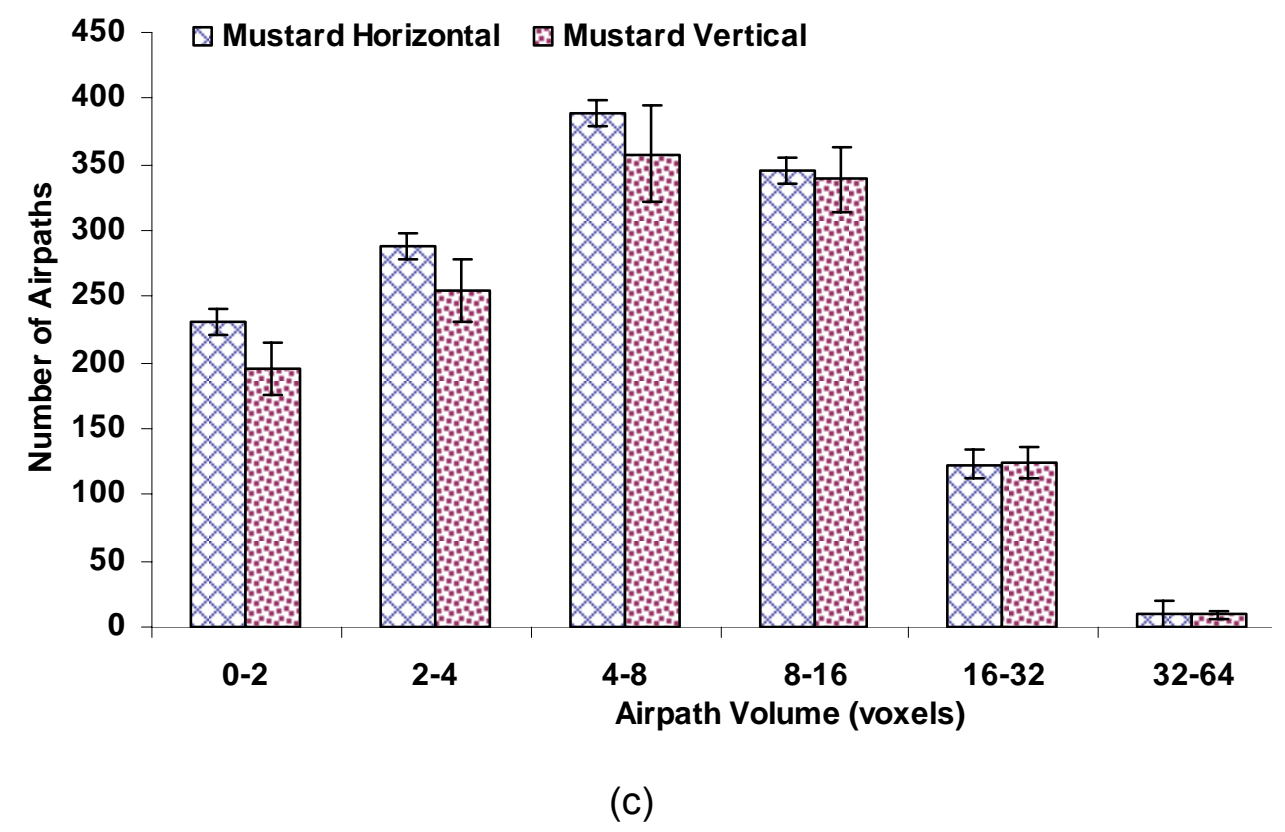

Figure 4. 3D airpath volume distribution in (a) Barley bulk, (b) Flax seed bulk, (c) Mustard bulk.

Thickness of airpath (Sr.Sp)

Air path thickness is calculated three dimensionally from 2D images with cylinder rod model (Parfitt et al. 1987).

$$
S r . S p=\operatorname{Sr} . T h \times\left(\left[\left(\frac{4}{\Pi}\right) \times\left(\frac{T V}{S V}\right)\right]-1\right)
$$

Where TV is the total volume of interest, SV is the solid volume, Sr.Th $=2$ / (Surface to Volume ratio) (Parfitt et al. 1987). Physically, this represents the diameter of a cylinder having volume and length equal to the volume and length of the airflow path.

Air paths with mean thicknesses (1 to 9 pixel thickness) are more in barley and flax seed bulk than in the mustard bulk (Figure 5). Air paths with almost same thickness are present in both the horizontal and vertical direction of mustard bulk compared to barley and flax seed bulks. 


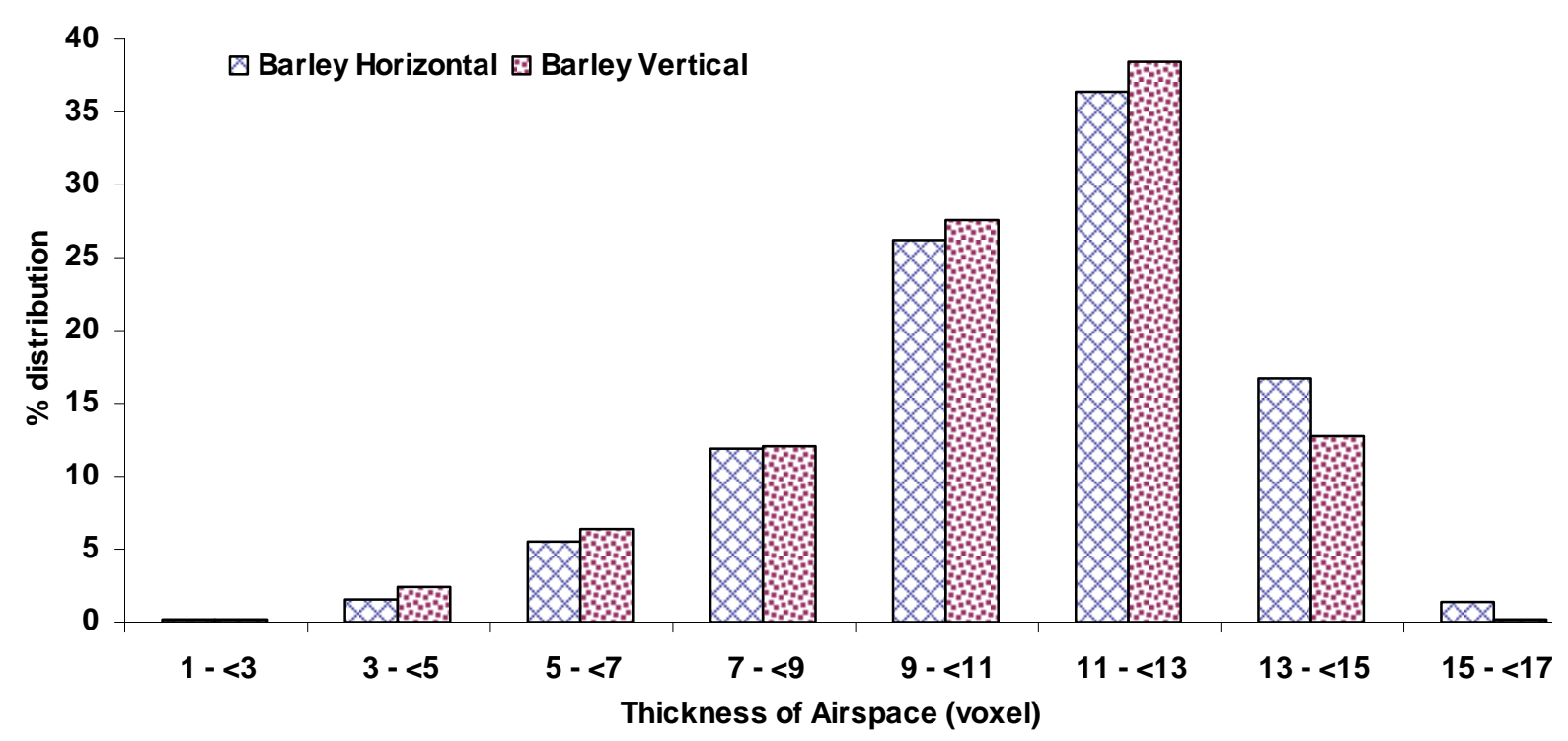

(a)

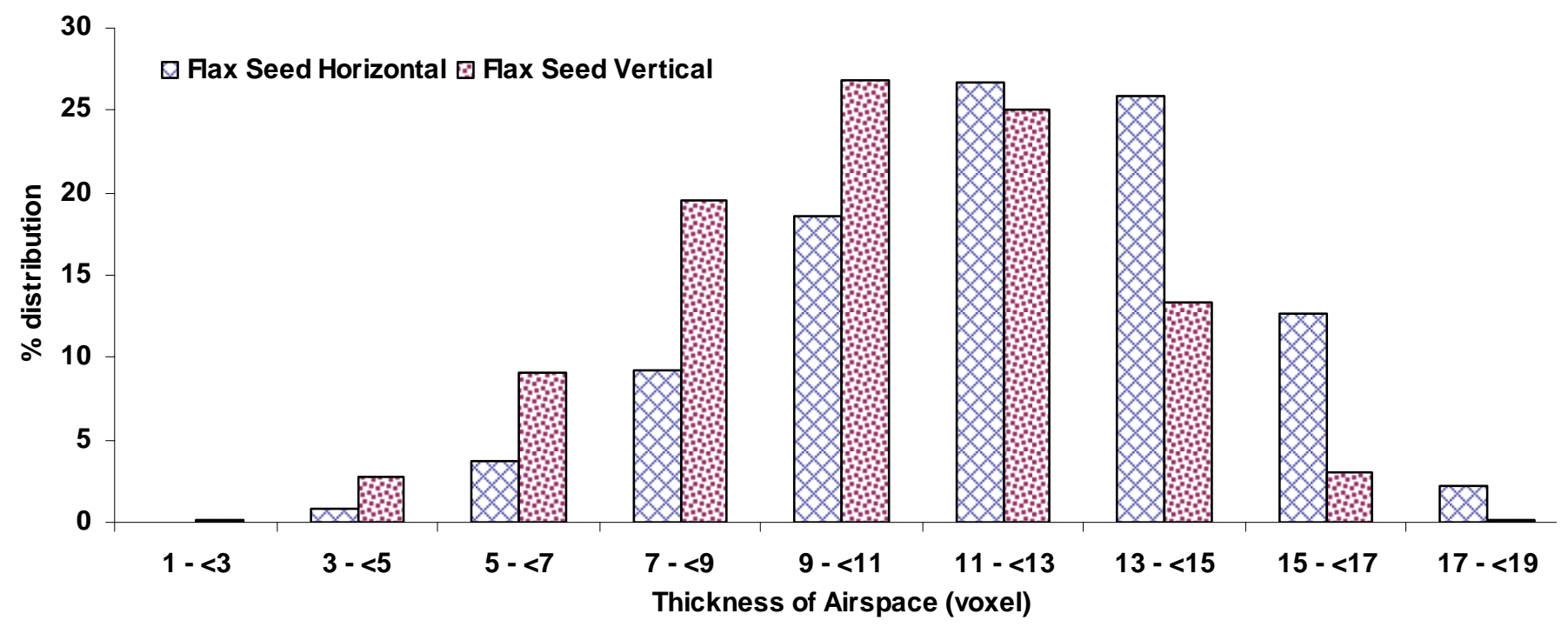

(b) 


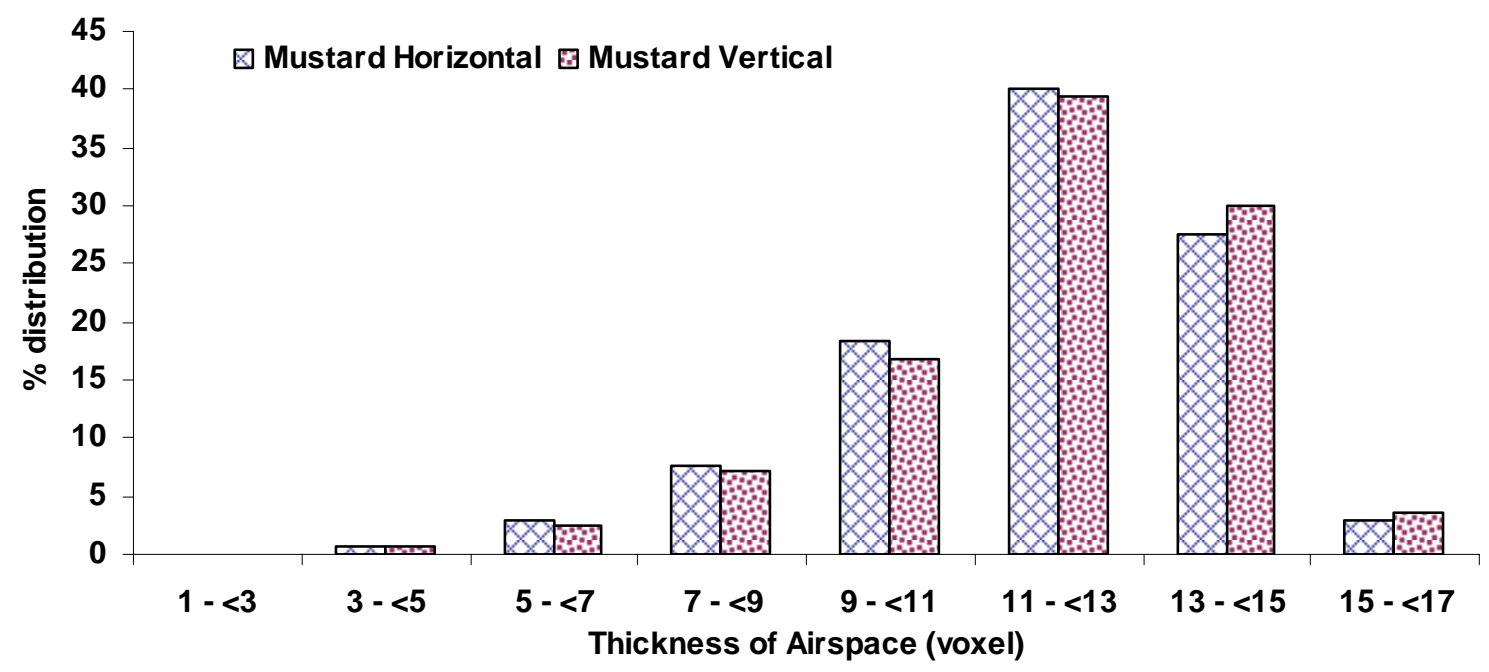

(c)

Figure 5. Air path thickness distribution in (a) barley bulk, (b) flax seed bulk, (c) mustard bulk.

\section{Fragmentation index (Fr.I)}

Fragmentation index is an index of connectivity of airspace (inside grain bulks) (Hahn et al. (1992). They calculated an index of relative convexity or concavity of the total surface, on the principle that concavity indicates connectivity (and the presence of "nodes"), and convexity indicates isolated disconnected structures (struts). Fr.I is calculated in 3D, by comparing area and perimeter (or volume and surface, respectively) of binarised solid before and after an image dilation.

$$
\text { Fr.I }=\left(\frac{P_{1}-P_{2}}{A_{1}-A_{2}}\right)
$$

Where $P$ and $A$ are solid area and perimeter, and the subscript numbers 1 and 2 indicate before and after image dilation. Lower fragmentation index signifies better connected lattices while the higher values of Fr.I indicates more disconnected void (air path) structures.

Air paths are more disconnected in the horizontal direction of barley and flax seed bulk than in the vertical direction (Figure 6). In mustard bulk, air path connectivity is same in both the directions of the grain bulk. There are more disconnected air path structures in the mustard bulk followed by flax seed and barley bulk. The fragmentation index also explains the longer air traverse time in the barley and flax seed bulk than the mustard bulk during drying. 


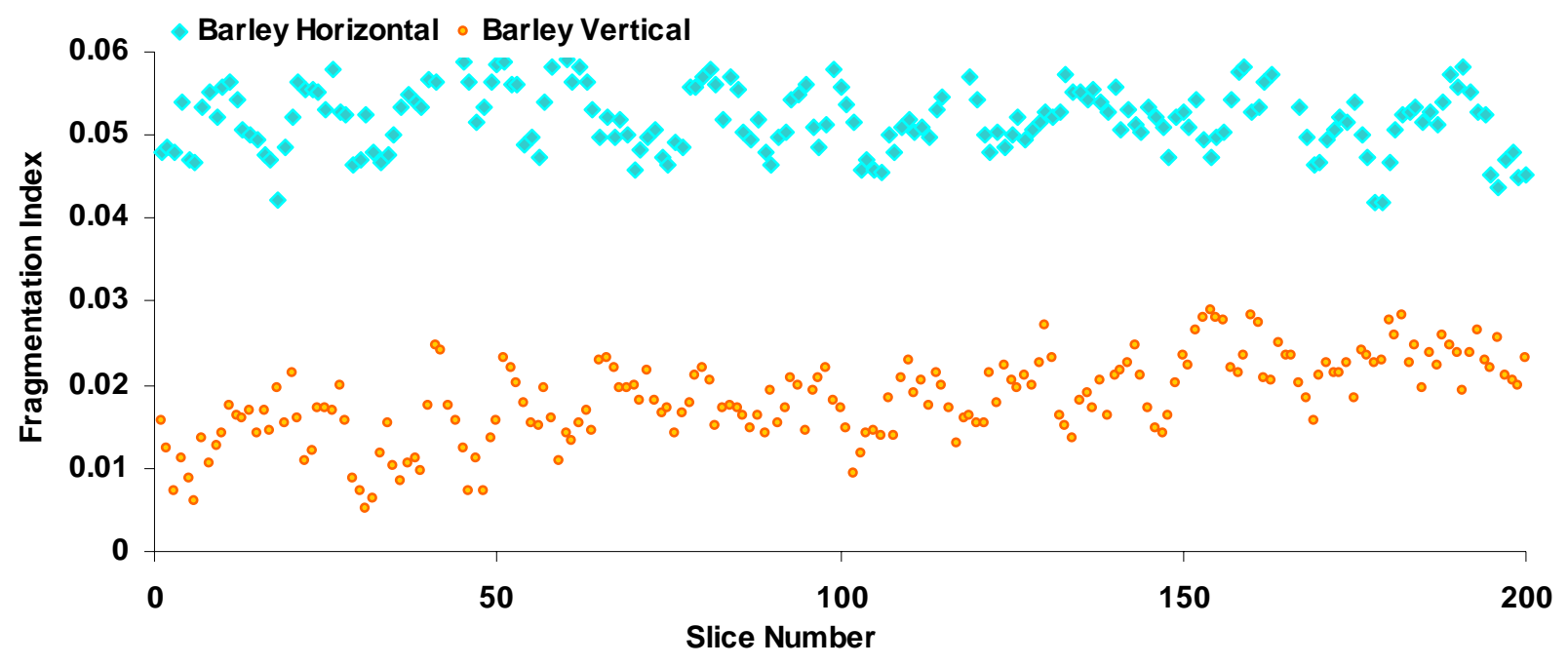

(a)

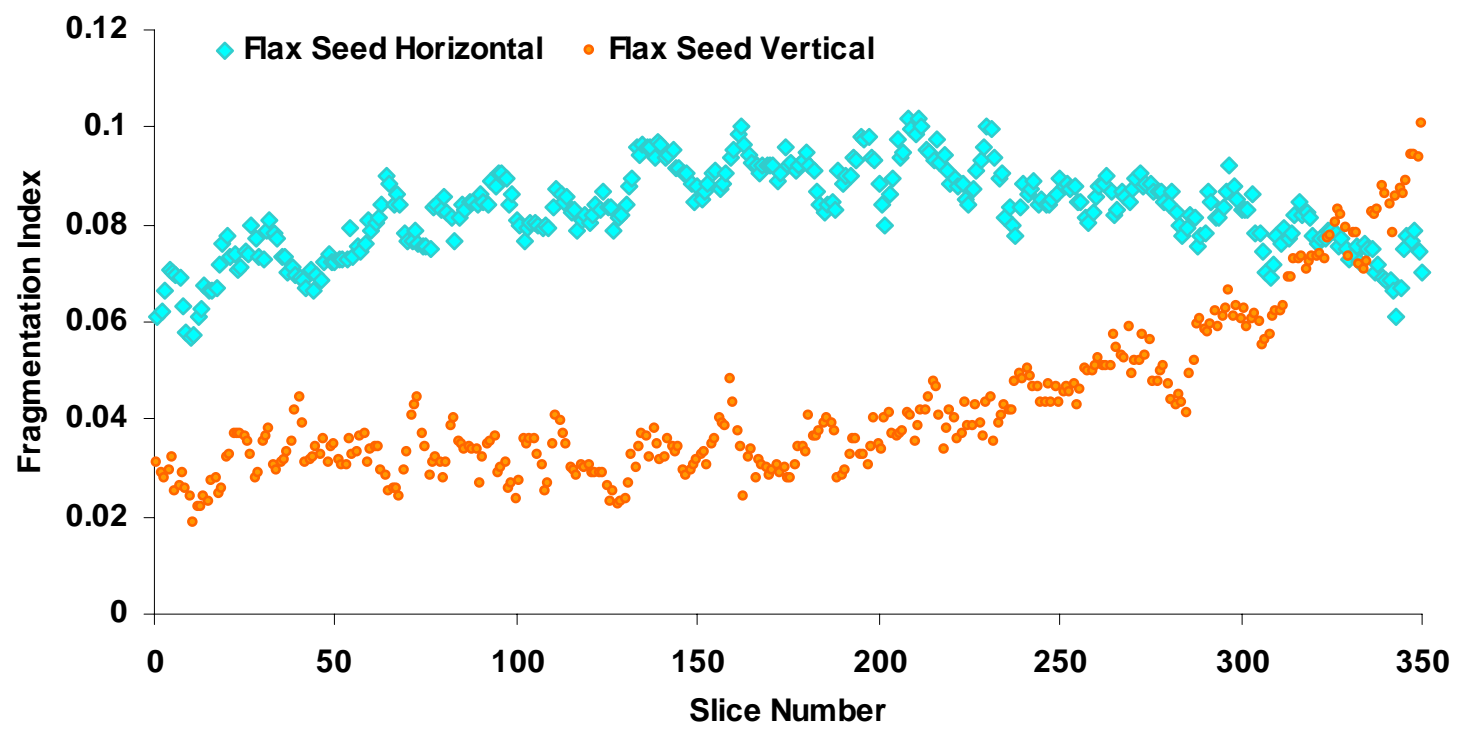

(b) 


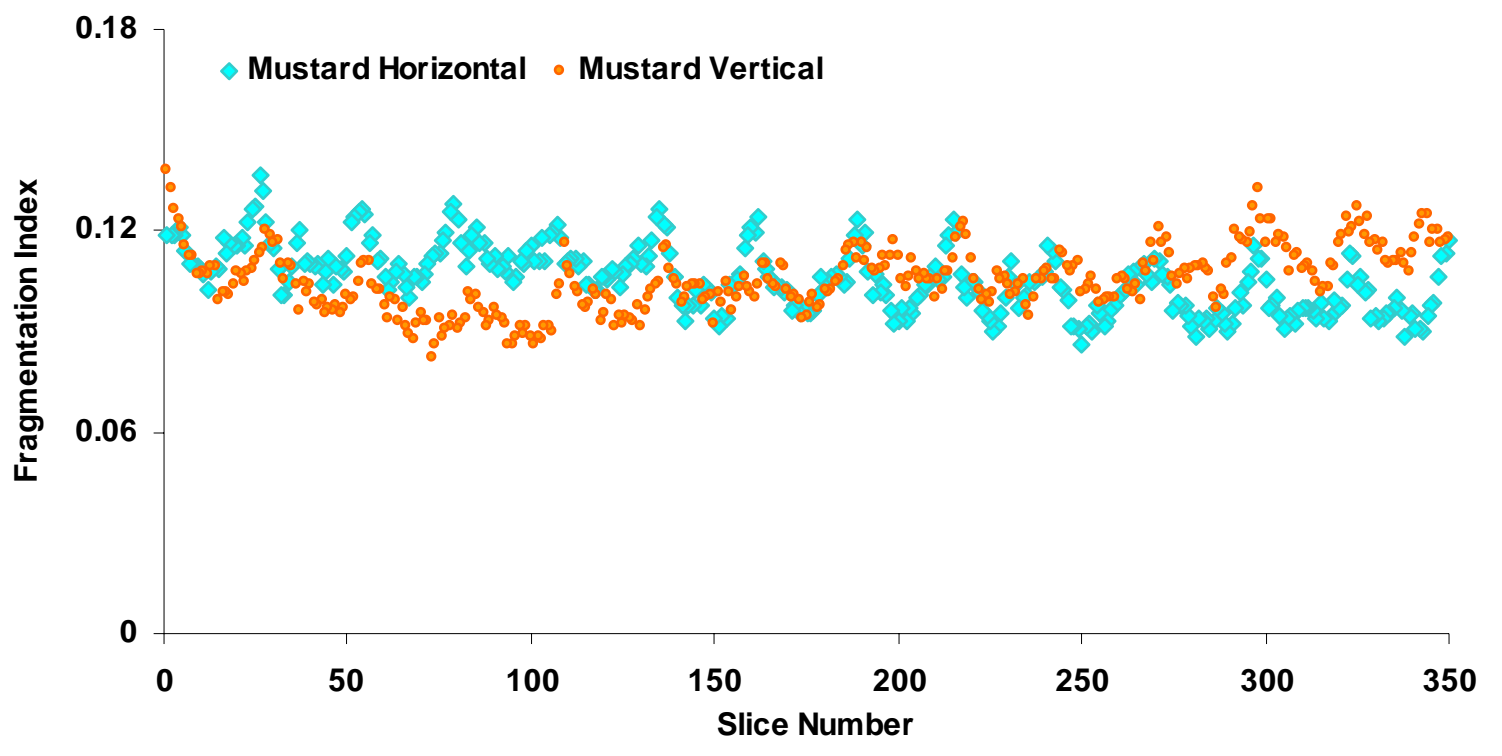

(c)

Figure 6. Fragmentation index distribution for (a) barley bulk, (b) flax seed bulk, (c) mustard bulk.

\section{EULER NUMBER (Eu.N)}

Euler number is also an indicator of connectedness of a 3D complex structure. It measures the degree to which parts of the object are multi connected (Odgaard and Gunderson, 1993). The Euler-Poincare formula for a 3D object $X$ is:

Eu.N $=\beta 0-\beta 1+\beta 2$

where $\beta 0$ is the number of objects, $\beta 1$ is the connectivity and $\beta 2$ is the number of enclosed cavities. Euler analysis provides a measure of connectivity density indicating the number of redundant connections between void (airpath) structures per unit volume.

The Euler number is more in horizontal direction to airflow of barley and flax seed bulk than the vertical direction, representing more inter nodal structures in the horizontal direction (Figure 7). The number of inter nodal structures are less in barley and flax seed bulk compared to that of mustard bulk. The number of inter nodal structures are almost same in both the horizontal and vertical direction of the mustard bulk. 


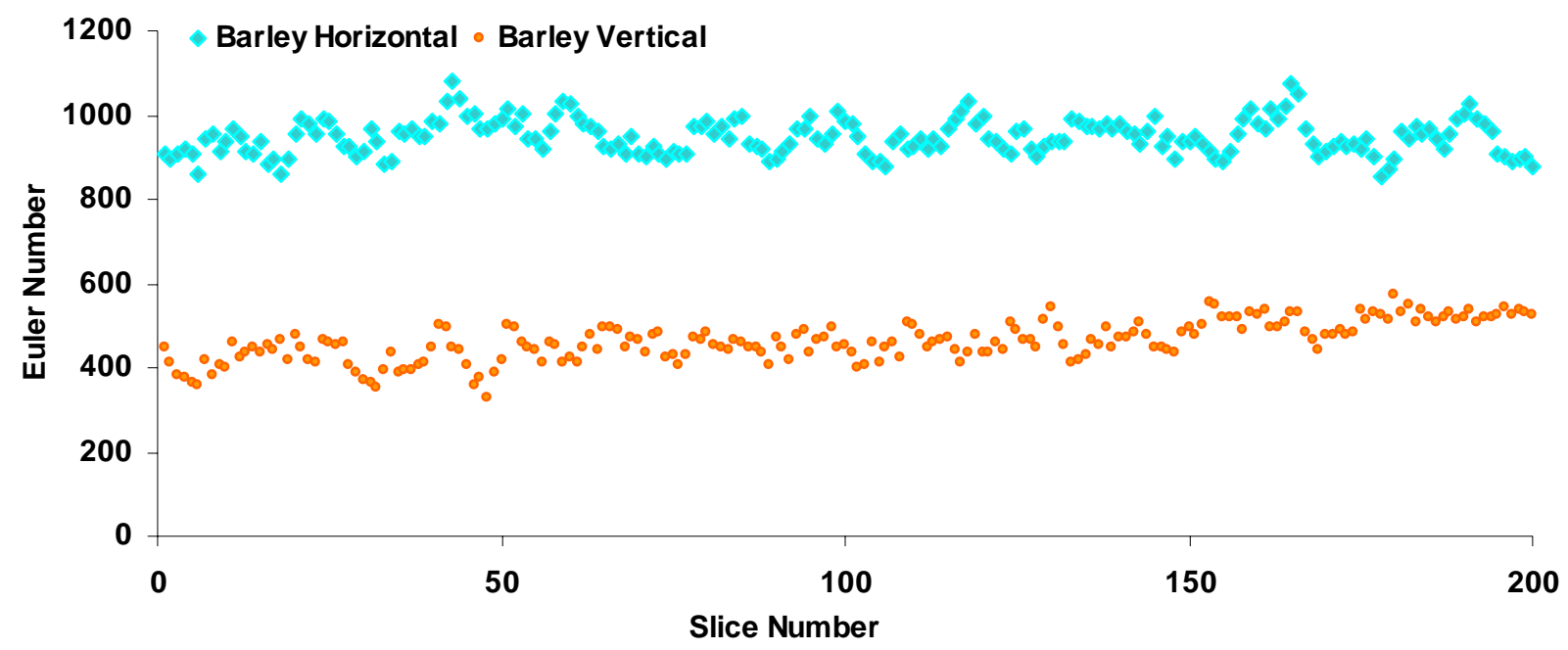

(a)

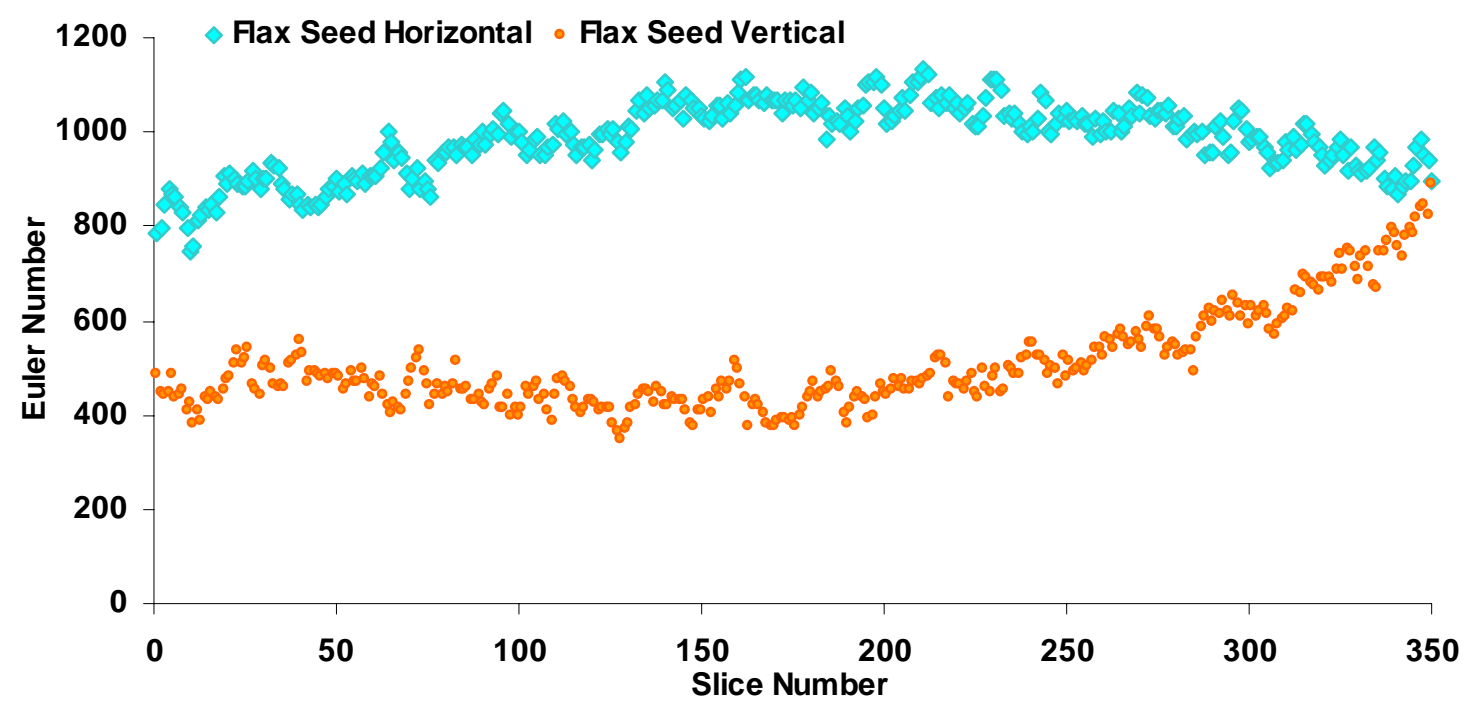

(b) 


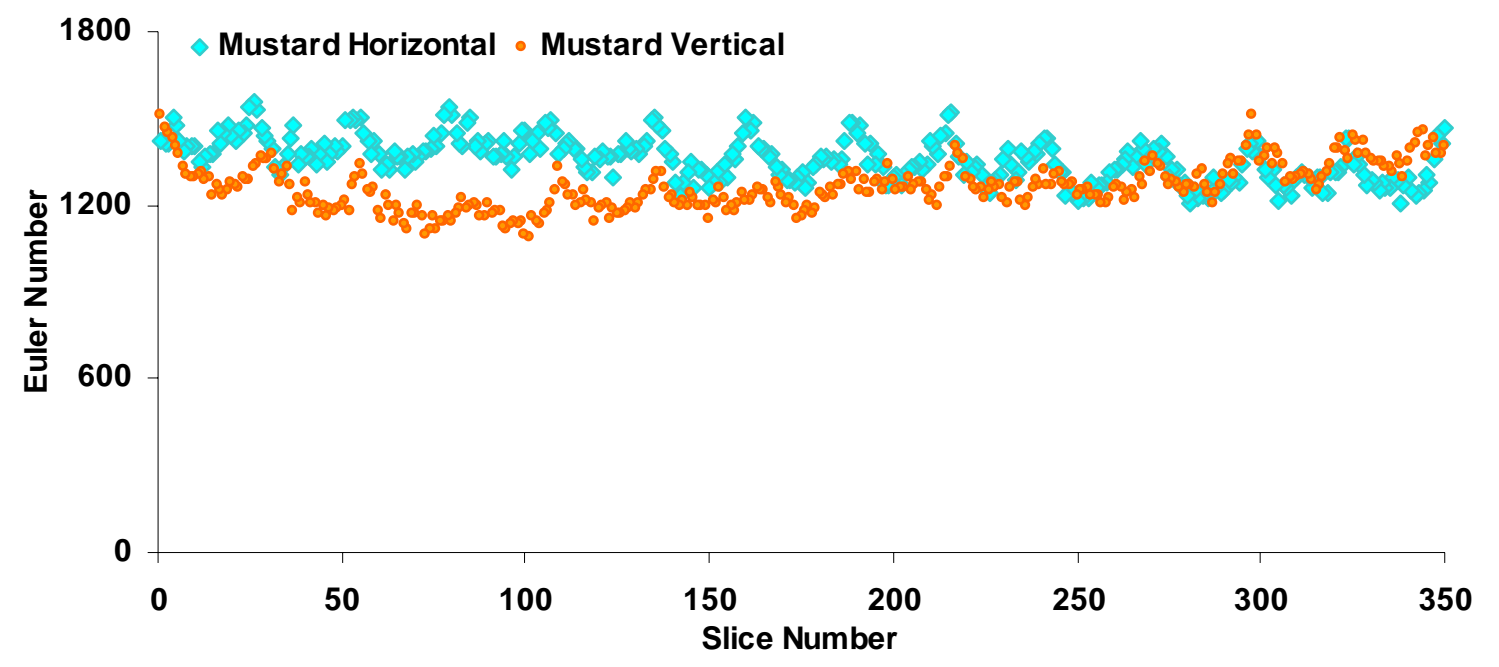

(c)

Figure 7. Euler number distribution in (a) barley bulk, (b) flax seed bulk, (c) mustard bulk.

\section{STRUCTURE MODEL INDEX (SMI)}

Structure model index is a qualitative parameter which indicates the relative prevalence of rods and plates in a 3D structure. SMI involves a measurement of surface convexity. This parameter is of importance which is characterised by a transition from plate-like to rod-like architecture. An ideal plate, cylinder and sphere have SMI values of 0,3 and 4, respectively. The calculation of SMI is based on dilation of the 3D voxel model by artificially adding one voxel thickness to all binarised object surfaces (Hildebrand et al. 1997). SMI is derived as follows:

$\mathrm{SMI}=6 \times\left(\mathrm{S}^{\prime} \times \mathrm{V} / \mathrm{S}^{2}\right)$

where $S$ is the object surface area before dilation and $S^{\prime}$ is the change in surface area caused by dilation. $\mathrm{V}$ is the initial, undilated object volume.

The SMI is lower for barley and flax seed bulk than the mustard bulk (Table 1). The values of SMI indicate that the air spaces in horizontal direction of barley and flax seed bulk are towards a rod like architecture than the plate like architecture. The architecture difference in both the directions of the grain bulk also influences the air flow movement in grain bulk. There is no significant difference between the SMls in horizontal and vertical direction of mustard bulk. This explains that the shape of air spaces inside pea bulk is same (rod like) in both the directions. This means that all the mustard seeds were equally spaced among themselves during packing in both the horizontal and vertical directions to airflow. 
Table 1. Structure model indices for barley, flax seed and mustard seed bulks

\begin{tabular}{ccc}
\hline Grain & Direction of airflow & Structure Model Index (pixels) \\
\hline \multirow{2}{*}{ Barley } & Horizontal & 1.23 \\
& Vertical & 0.85 \\
Flax Seed & Horizontal & 1.61 \\
& Vertical & 1.34 \\
Mustard & Horizontal & 1.82 \\
& Vertical & 1.85 \\
\hline
\end{tabular}

\section{AVERAGE AIRSPACE AREA}

This parameter is a useful indicator of structural connectivity. This is determined from the slice by slice $2 \mathrm{D}$ analysis of the X-ray CT images.

Airspace area increases from the bottom of the grain bulk to the top for barley and flax seed bulk in the vertical direction (Figure 8). This indicates the compaction of grain bulk in the vertical direction. Airspace area is higher in the vertical direction than in the horizontal direction of barley and flax seed bulk whereas Airspace area is same in both the directions for mustard bulk.

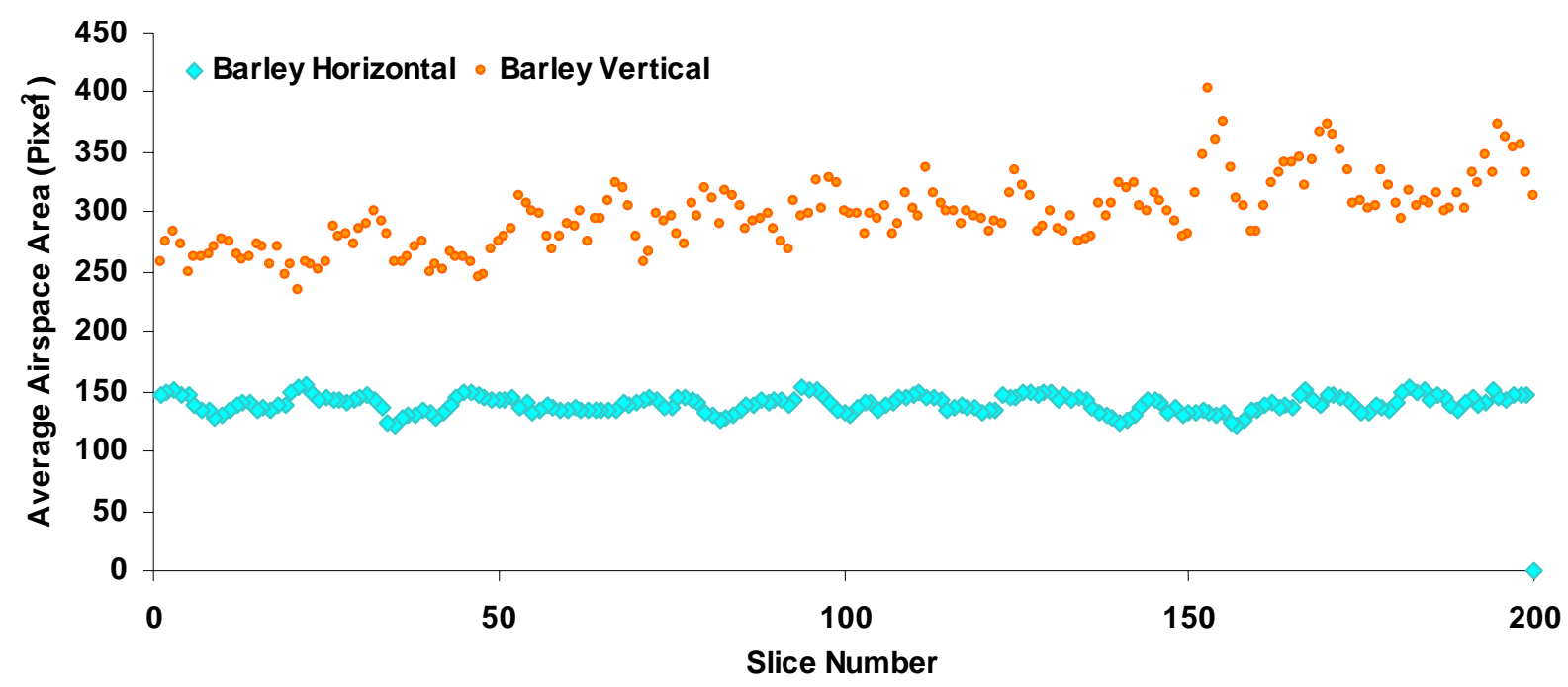

(a) 


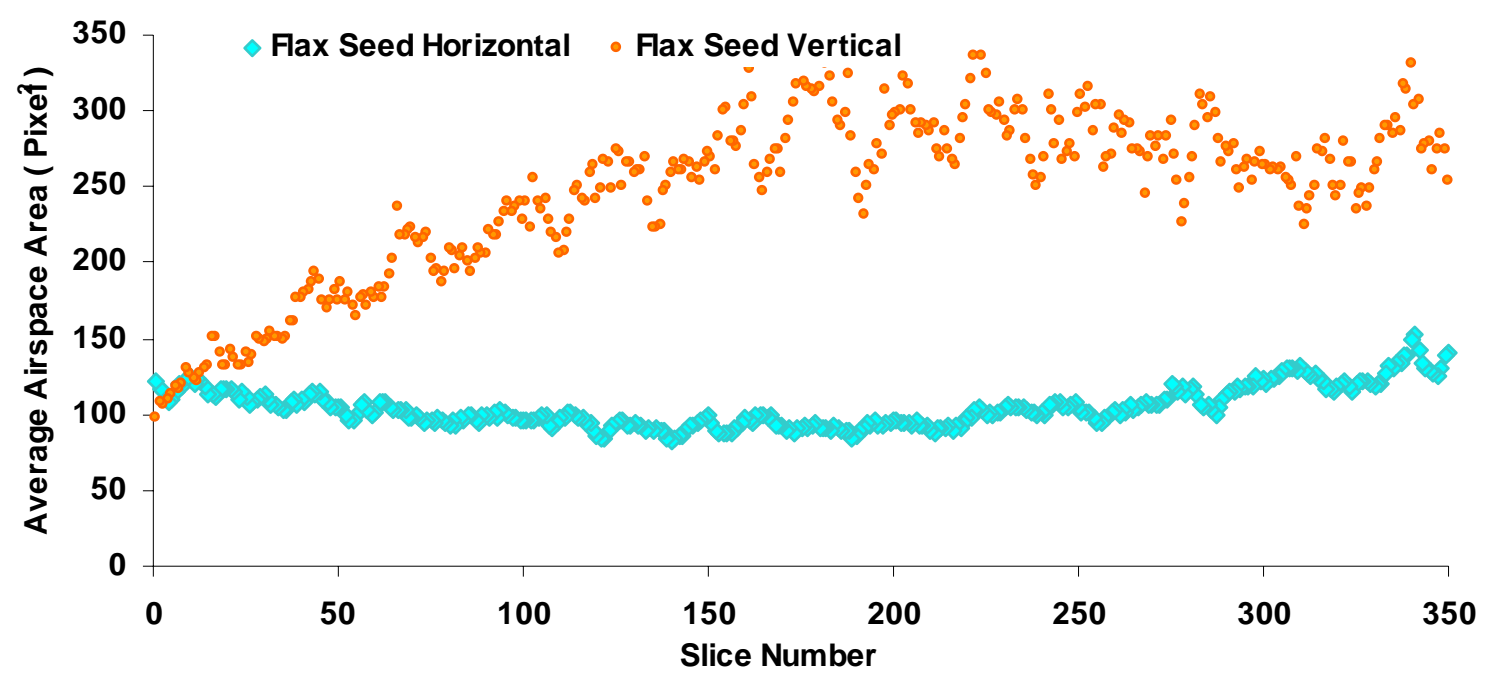

(b)

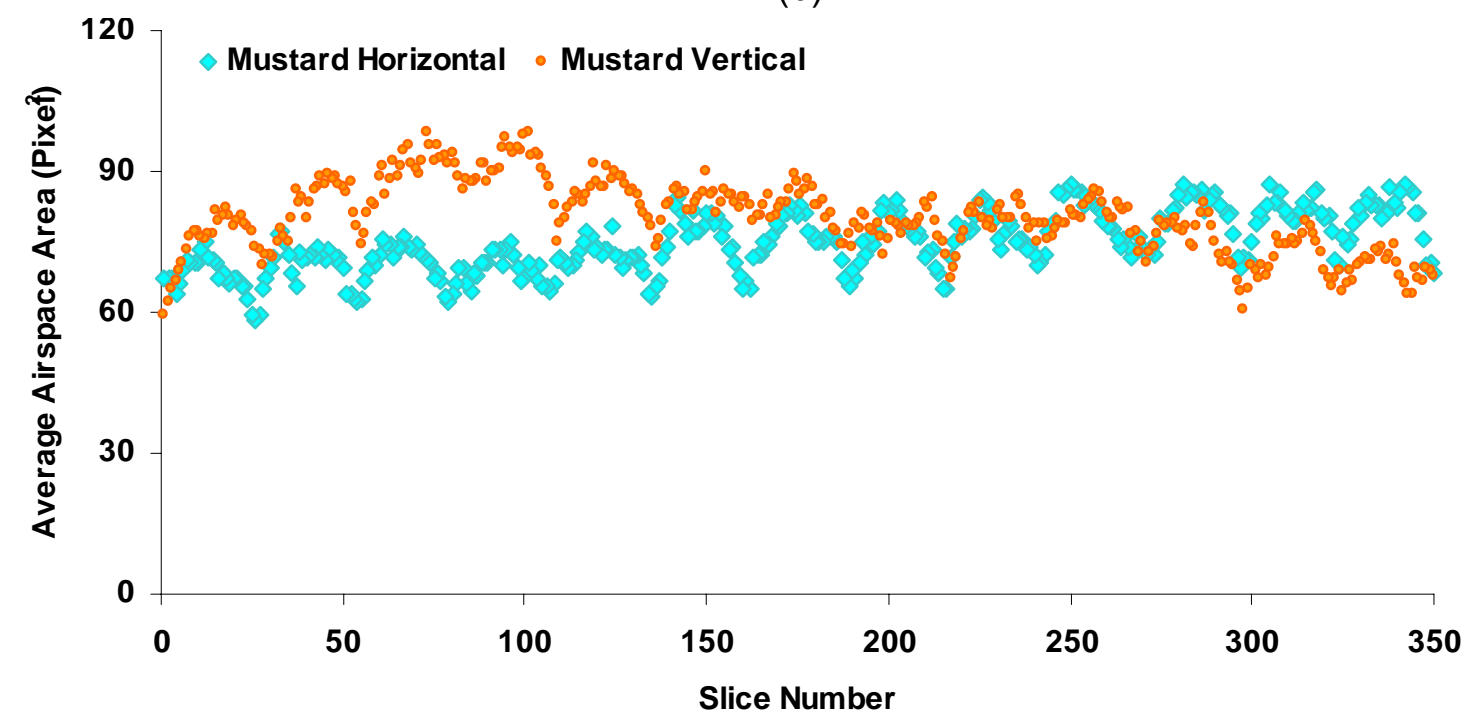

(c)

Figure 8. Average airspace area in each slice of X-ray CT images of (a) barley, (b) flax seed, (c) mustard grain bulk.

\section{Future recommendation}

According to Poiseuille's law, local hydraulic conductivity is dependent on the dimensions of the pore.

$$
K(r, L)=\frac{\Pi r^{4}}{8 \mu L}
$$

where $\mathrm{K}=$ hydraulic conductivity, $\mathrm{r}=$ aperture of the pore, $\mathrm{L}=$ length of pore space, $\mu=$ viscosity of the fluid. 
By calculating the local conductivity associated with each pore, over all permeability of fluid flow inside grain bulks can be determined. Pore morphology based models can be developed and simulated to determine the pressure-saturation curves and for calculating the distribution of wetting and non-wetting phases of fluid flow inside the 3D geometry of grain bulk. The morphometric features of pore geometry inside grain bulks quantified in this study will be used for validating such models.

\section{Conclusions}

Three dimensional X-ray CT image analyses is an effective method to determine pore space geometry inside grain bulks. Technique for the reconstruction of the void space 3D model inside grain bulks using X-ray CT images is described. Morphometric parameters measured on the 3D X-ray tomographic data using the image processing algorithms revealed information about the connectivity of the airpath structure and allowed for the estimation of airpath size distribution. Connectivity parameters such as Euler number and fragmentation index explains the reason for airflow resistance difference in horizontal and vertical directions of the grain bulks. The shape of the grain influences the nature and geometry of the pore space inside grain bulk. There is a strong feasibility of developing a pore network model for determining fluid flow permeability with the help of measured morphometric features.

\section{Acknowledgements}

The authors gratefully thank the Canada Research Chairs Program and the Natural Sciences and Engineering Research Council of Canada for their financial support for this study. The authors also thank the centre for Bone and Periodontal Research, Montreal, Canada for providing access to CT Analysis software.

\section{Reference}

ASAE Standard. 2003. Resistance to airflow of grains, seeds, other agricultural products, and perforated metal sheets. ASAE D272.3 DEC01. St. Joseph, MI.: American society of Agricultural Engineers.

Drebin, R.A., D.R. Ney, E.K. Fishman, and D. Magid. 1990. Volumetric Rendering of Computed Tomography and Data: Principles and Techniques. IEEE Computer Graphics and Applications 10(2): 24-31.

Hahn, M., M. Vogel, M. Pompesius-Kempa, and G. Delling. 1992. Trabecular bone pattern factor - a new parameter for simple quantification of bone micro architecture. Bone 13: $327-330$.

Hildebrand, T. and P. Ruegsegger. 1997. Quantification of bone micro architecture with the structure model index. Computer Methods in Biomechanics and Biomedical Engineering 1: 15-23.

Irvine, D.A., D.S. Jayas, N.D.G. White, and M.G. Britton. 1992. Physical properties of flax seed, lentils, and fababeans. Canadian Agricultural Engineering 34: 75-81.

Jayas, D.S., S. Sokhansanj, E.B. Moysey, and E.M. Barber. 1987. The effect of airflow direction on the resistance of canola (rapeseed) to airflow. Canadian Agricultural Engineering 29: $189-192$.

Jayas, D. S., K. Alagusundaram, and D.A. Irvine. 1991. Resistance to airflow through bulk flax seed as affected by the moisture content, direction of airflow and foreign material. Canadian Agricultural Engineering 33(2): 279-285. 
Kainourgiakis, M.E., E.S. Kikkinides, A. Galani, G.C. Charalambopoulou, and A.K. Stubos. 2005. Digitally Reconstructed Porous Media: Transport and Sorption Properties. Transport in Porous Media 58: 43-62.

Kumar, A., W.E. Muir. 1986. Airflow resistance of wheat and barley affected by airflow direction, filling method and dockage. Transactions of the ASAE 29: 1423-1426.

Lindquist, W.B. 2002. Quantitative analysis of three dimensional X-ray tomographic images, in Developments in X-ray Tomography III. In Proceedings of SPIE, 4503, 103-115. SPIE, Bellingham, USA. July 7-10.

Lorensen, W.E. and H.E. Cline. 1987. Marching cubes: a high resolution 3D surface construction algorithm. Computer Graphics 21: 163 - 169.

Neilsen, J. 1998. Pressures from flowing granular solids in silos. Philosophical Transactions of the Royal Society A 356: 2667-2684.

Odgaard, A. and H.J. Gundersen. 1993. Quantification of connectivity in cancellous bone, with special emphasis on 3-D reconstructions. Bone 14: 173-182.

Parfitt, A.M., M.K. Drezner, F.H. Glorieux, J.A. Kanis, H.Malluche, P.J. Meunier, S.M. Ott, and R.R. Recker. 1987. Bone histomorphometry: standardization of nomenclature, symbols and units. Journal of Bone and Mineral Research 2: 595-610.

Toye, D., M. Crine, and P. Marchot. 2005. Imaging of liquid distribution in reactive distillation packings with a new high-energy x-ray tomography. Measurement Science and Technology 16: 2213-2220.

Turner, M., A. Sakellariou, C. Arns, R. Sok, A. Limaye, T. Sendent, and M. Knacksted. 2003. Towards modelling regolith permeability with high resolution X-ray tomography. Advances in Regolith. Adelaide, Australia: CRC LEME.

Velasco, L., M.M. Jose, and A. Haro. 1998. Application of near-infrared reflectance spectroscopy to estimate the bulk density of ethiopian mustard seeds. Journal of the Science of Food and the Agriculture 77: 312-318. 